\title{
Immersive 3D Virtual and Gamified Environment: The Learner Model Approach
}

\author{
Alvino Moser ${ }^{1}$ Phd, Neri dos Santos ${ }^{2}$ Phd, Luiz Fernando Corcini ${ }^{3} \mathrm{MSc}$, \\ ${ }^{I}$ (Education, Master's program in Education and New Technologies/ Centro UniversitárioInternacional - \\ UNINTER, Brazil) \\ ${ }_{2}^{2}$ (Education, Engeneering, Pontifície Universidade Católica do Paraná - PUC-PR, Brazil) \\ ${ }^{3}$ (Education, Information and Communication Technology, FaculdadesIntegradas Santa Cruz de Curitiba - \\ FARESC, Brazil)
}

\begin{abstract}
Immersive and gamified virtual environments have great potential to add value to the learning process of content inside and outside the classroom. However, this requires teachers or mediators to adopt new approaches and methodologies. So this paper developsa product,based on self-determination and connectivism theories and collaborative learning, for application and evaluation in postgraduate environments. The methodological procedures used were predominantly the bibliographical research and the conceptual model that associates learning mechanics with game mechanics. The developed product uses an open-source server platform for metaverse hosting. The interface between the virtual world and the intelligent tutoring system is given through a web server and for the data storage a relational database is used. It was verified teachers great interest with the application's possibilities and the students with the interest in exploring the environment and learning from it, which demonstrates the consistency of the conceptual model. Future investigations could use the questionnaire in larger samples either focusing on other levels of education (undergraduate, high school, etc.) or even within other disciplines.
\end{abstract}

Keywords: Educational Technology, Gamification, Immersive Virtual Reality in Education, Intelligent Tutoring System, Learning Virtual Environment.

\section{Introduction}

According to Oliveira (2013) [1]and Horizon Report (2017) [2], the use of Information and Communication Technologies (ICT) and, in particular, virtual and gamified environments in education, presentsitself as an alternative that enables innovative experiences for both students and teachers. Some authors, such as Meira(2012) [3] and Zicherman(2012) [4], point out that decontextualized content teaching based on decorations and teachers' centered as a source of knowledge, keeps the student in a passive and individualistic attitude, exactly the opposite of what wishes for a professional that companies would like to hire. In addition, we have tedious and unattractive classes.

From strategic approach, Moura and Carvalho (2010) [5] emphasize that globalization and the job market's evolution require new skill's acquisition... and these new skills require new contexts and learning strategies. The same authors also emphasize that "the understanding of how students learn is central to the success of any educational strategy".

In thiscontext, this paper intends to present a product based on a new approach to classroom instruction, inperson or online context, using both the Immersive 3D Virtual and GamifiedEnvironmentand Intelligent Tutoring System concepts. This paper's first part deals with the theoretical foundation in student's learning, followed by a brief exposition about how it is achieved by immersive 3D virtual and gamified environments supported by ITSs, based on Abt(1987) [6], Nwana(1990) [7], Ryan \& Deci (2000) [8], Huizinga (2000) [9], Siemens (2005) [10], VanLehn(2006) [11], Moura \& Carvalho(2010) [5],Nkambou(2010) [12], Prensky(2011) [13], Kim(2012) [14], Meira(2012) [3], Zicherman(2012) [4], Gee (2013) [15] andGraesser(2013) [16]. Then, there is a brief description of the methodology used and the motivational aspects that led to this product'sdevelopment, followed by product'spurpose and functionalities , based on the Carreira(2009) [17]'s methodology (visualization, manipulation and experimentation).Followed by conceptual model and implementation design presentation of the experiment and achieved results. And then the collection and analysis of the data obtained with the product's experimentation, the results and final considerations.

\section{Theoretical Foundation}

Learning is a very complex human activity that has been investigated and modeled through various pedagogical theories through the ages[18]. Both E. Chaves (1999) [19] and Moser (2016) [20] insist on the fact that no one learns in the other's place because it is a process that takes place inside the individual. The OECD's (Organization for Economic Co-operation and Development) document in the pedagogical innovations project 
of 2012 (The Nature of Learning - Using Research to Inspire Practice)support this idea: Learning should be student-centered, following the socio-constructivist proposal.

Likewise, some researches point that learning process is social nature and has emotional and motivational predominant influence. According to Siemens [10], the knowledge and, therefore,the learning is society's mediated individual construction, thus being a co-construction.

\subsection{Virtual and Immersive Learning Environment}

According to many authors, three-dimensionalvirtual worlds are environments in which the real world can be simulated. Users can move using virtual representations called avatar and they can interact with each other and with environment objects in a synchronous way[21].Use this kind of immersive worlds provides detailed and rich educational experience, immersion sense and interaction possibilitieswith various educational resources. [22].Yilmaz [21] also points out that 3D virtual worlds differ from other learning environments in its real world similarity, providing opportunities for more effective interaction and communication.

Teaching-learning immersive environments denote a possibility for learner's development differently by immersion in scenarios that can recreate classrooms, laboratories, conferences and different contexts to explore.Virtualization environments, according to [1] is an alternative that brings numerous innovative possibilities and can modify parameters, such as: student differentiation and motivation; geographically spaced individuals learning process; knowledge's collective constructionin specific environments for such purposes, among others.

But, in the other hand, Moura et.al [22]warns that learning process inside virtual worlds traditionally does not take care about learner's individual characteristics and contexts.Another key point is how the content is organized and presented to learner, because, according to Munhoz[23], the scenario's storytelling is as important as the content to be taught. It is a goodstory and a consistent script that draw students attention,motivating them for learning and not the opposite.

One feature that attracts many teachers, researchers and even educational institutions to develop projects using the Virtual Worlds is the ability to recreate reality and to test conditions with minimal budget constraints compared to real world ones. Beyond that real worldrecreation or simulation, there is also the possibility of creating scenarios, scripts and fictional world'sstories where the limit is the developers'creativity. However, as Salleb reports, researchers conclude that no VLE (Virtual Learning Environment) can replace the real life interaction between student and teacher. [22].

Thus, we believe that the development and use of digital roadmap for logic modeling immersive content, contextualizing the content to be learned and the way they are treated is extremely important to the success and effectiveness of 3D immersive content. The product developed in the project mentioned in this paper uses the ITS's principles (also known as intelligent agents with pedagogical features) to solve part of the problem presented below: the learners' individual characteristics identifications and contexts (so called The Learners Model).

\section{2. Intelligent Tutoring System (ITS)}

According to Nwana [7], the incorporation of artificial intelligence (AI) techniques into education in order to produce educationally useful computer artefacts dates back to the early 1970s and ITSs are a way in which AI techniques are being applied to education. In more specific worlds, we can say that the ITS's idea is to build computers that could "think" like humans and perform any task that were associated with human thought [24], such as the instruction. In a formal way, intelligent tutoring systems (ITSs) are computer programs that are designed to incorporate techniques from the AI community in order to provide tutors which know "what" they teach, "who" they teach and "how" to teach it[7] and some authors point out that there has been an effort to employ the ITS in traditional learning because they have the potential to provide learning environments with greater wealth of resources and exploitation of contextualized social aspects of learners [22].

A software is considered an ITS if you have three characteristics [25]:

- $\quad$ Contain one domain knowledge to act as a human expert (Expert Knowledge Module);

- Be able to assess the learner's knowledge of stage (LearnerModel Module);

- Should perform a teaching strategy that minimizes the difference between the knowledge of the expert and the novice (Tutoring Model Module);

- Be able to interact with the learner through a communication channel (User Interface Module);

In this general architecture, the Expert Knowledge Module comprises the facts and rules of the particular domain to be conveyed to the student[7]. The Student or Learner Model Module refers to the dynamic representation of the emerging knowledge and skill of the student. Nwana [7] points out that this model should include all those aspects of the student's behavior and knowledge that have possible repercussions on his/her 
performance and learning.The Learner Model Module's functions are classified in six types and are listed below:

1) Corrective type: to help eradicate bugs in the student's knowledge.

2) Elaborative type: to help correct 'incomplete' student knowledge.

3) Strategic type: to help initiate significant changes in the tutorial strategy other than the tactical decisions of 1 and 2 above.

4) Diagnostic type: to help diagnose bugs in the student's knowledge.

5) Predictive type: to help determine the student's likely response to tutorial actions.

6) Evaluative type: to help assess the student or the ITS.

The Tutoring Moduleis the part of the ITS that designs and regulates instructional interactions with the student. This module is referred to as the teaching strategy or the pedagogic module[7]. Finally, the User Interface Module is the communicating component of the ITS which controls interaction between the student and the system. In both directions, it translates between the system's internal representation and an interface language that is understandable to the student [7]. Fig. 1, below shows a ITS's general architecture representation.

Based on the explanation above, we can realize that Intelligent Agents and Intelligent Tutoring Systems can perform various tasks in a VLE to assist the teacher in evaluating the students' performance, for example: monitoring the apprentices activities, capture automatically their contextual information, such as a preference for a particular type of content, the difficulty in resolving certain activity, frequency of resources use and to performing the learner's direction on the educational content recommendation [22].

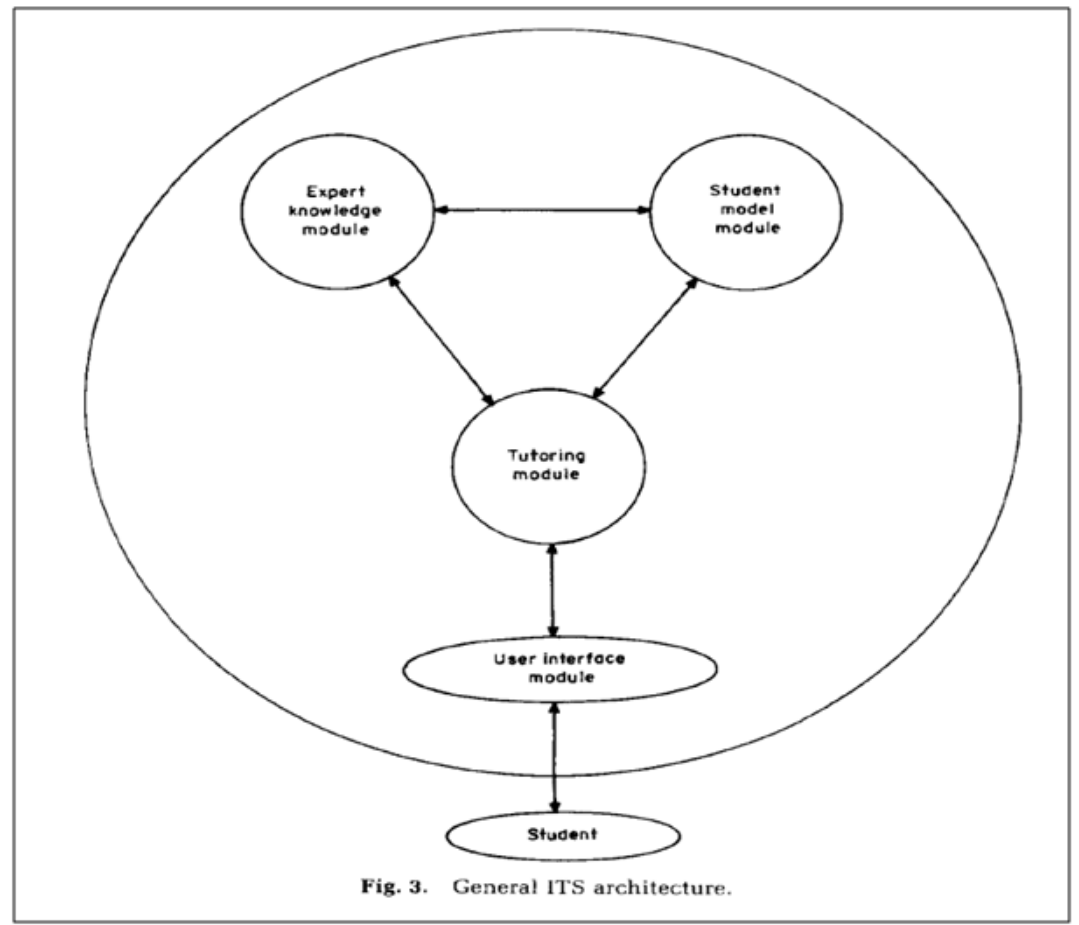

Figure 1 - Intelligent tutoring system'sgeneral architecture [7]

\section{Motivation}

The first idea of this project began with the perception, based on the experience of more than a decade teaching in undergraduate courses, that the students'interest in the subjects addressed in the class and the students learning predispositionhas becomeless and less present. It was assumed that the content itself represented something relevant to the student's professional life, so that to improve the students motivation and engagement and to bring him closer to meaningful learning, a proposal arises to change the way or method of presentation of the contents. In this context, a proposal was made whose problem to solve was the development of a serious game to be applied in undergraduate and postgraduate environments. As content to be dealt with by the Environment, subjects of the Artificial Intelligence and Technological Mediation disciplines were chosen because of author's proximity to the content. It is important to highlight here that the product (Virtual Immersive Environment) developed was designed to serve as a platform for teaching any other content chosen at undergraduate or postgraduate level. 


\section{The Project'spurposeand its Functionalities}

Unlike traditional games, in this Immersive Learning Environment, the goal is not to get the best score, nor to stay in the top ten for a longer time. Based on Bartle (1996) [26], Marczewski (2013) [27] and Kim $(2012,2014)$ [14] [28], the player, in the proposed immersive virtual environment, also does not supposedto destroy the villains' boss, conquer territories or even destroy other players. The objective is to identify the student profile, based on the typology defined by the above mentioned authors, promoting their skills and improving their deficiencies - The ITS's learner model.

Gambling and game elements such as medals, points for collaboration and finished tasks, as well as progress bar are used in order to engage the student, as highlighted by Abt (1987) [6], Huizinga (2000) [9], Kapp (2012) [29], Meira (2012) [3], among others, not as a form of competition, but to provide a pleasant and immersive environment. Keeping the student interested in learning or improving his methods, participating in study groups, building knowledge in a collaborative way and bringing him closer to a scientific and questioning reasoning is the central focus of the project's proposal. Each student will have access to their own data and the teacher of the discipline, of course, will have all students data access. Another interesting feature that makes all the difference is that this projectdoes not aim to come to an end. It lasts for the courses program duration (undergraduate or graduate) or as long as the student intends to participate.

The project's development adheres to the self-determination theory (Deci \& Ryan, 2000)[8], whose occurrence conditions are presented below:

- Provide a feeling of competence or that the task is achievable;

- Provide a sense of autonomy or a sense of control over the task;

- Provide a sense of social relevance or relevance in performing the task;

In this context, within the Immersive Learning Environment, the student decides what he/she wants to learn first and also identifies what are his/her improvement needs. This is, as pointed out by Kapp (2012) [29], Prensky (2012) [13], the learning process becomes student responsibility and focused on him. So, teacher becomes a kind of a mentor or emancipator.

Regarding the functionalities, the solution developed consists of a serious game- three-dimensional Immersive Learning Scenario, which allows the student, through an avatar, to self-controlhis/herlearning process.The main functionalities are listed below:

- Allow the student to choose the appearance of their avatar;

- To present campus conducts rules;

- To provide content in various media;

- Tomonitor student activities within the environments available in the Scenario;

- Toidentify the weaknesses and competencies of each student, as well as their profile;

- To validate the student's progress through the proposition of activities;

- To allow students access to certain areas of the scenario only if they are properly emancipated for it;

- To allow the teacher full control over what should be presented and when it should be presented to students;

The Fig. 2, below, shows the project's Use Case Diagram

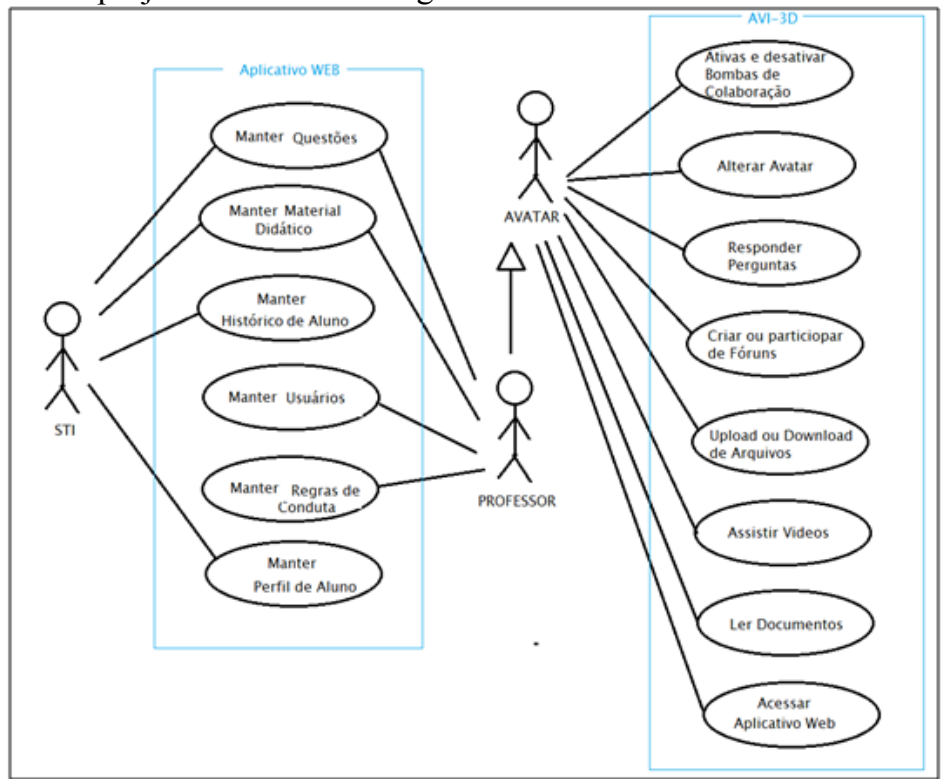

Figure 2 - Project's functionalities 


\section{Conceptual Model and Implementation Design}

Learning Mechanics - Game Mechanics (LM-GM) model is designed to allow different users to describe games based on different pedagogical approaches. In serious games, gameplay must support intrinsic experimental learning. It is therefore reasonable to postulate that the knowledge acquisition and training skills can be obtained through game mechanics such as quests, levels, medals, role plays, leaderboards, etc. The Fig. 3 below shows the LM-GM model applied in this project.

\subsection{LM-GM Model Explanation}

Once the learner just entered in Immersive 3D Virtual Environment for the first time, he/she will be presented to the game and will get the campus conduct code. In this case, as we can see in the Fig.3, below, the Learning Mechanisms (LM) used is represented by letter "a" and the corresponding Game Mechanics (GM) is defined by number "1".TABLE 1, below, show us that the Learning Mechanics corresponding to letter " $\mathrm{a}$ " is the "Instructional"and the Game Mechanics corresponding to number " 1 " is the Story Line/ Scenes".

In the next step, according to Fig.3, the learner/player is presented to the environment's tutorial, represented by letter "b" (Learning Mechanics) and by number " 2 ". So, in this gameplay moment, the learner was already presented for the environment's basic story line, read and accepted the conduct code and had access to the environment's basic tutorial, then, he/she can begins to explore, identify and discover the environment's learning objects, masked by letter "d" (Fig.3), corresponding to the select, collect and interact actions - number " 5 ". After this, the leaner is asked to collaborate and cooperate with others. . He/she also needs to manage results, goods and information - Letter " $\mathrm{f}$ " (LM) and number "6" (GM).

In this moment, the ITS - Learner Model Module - starts the learner's orientation and motivation acts letters "c" and "e" by capture/eliminate instructions (number " 3 " and "4"), for example, keeping learner in the game virtuous circle. Feedbacks and checkpoints are also used to keep the learner in line with the knowledge needs. In this moment game elements (medals, badges, etc.) are applied.

Table1 -LM-GM Model used in this project. Font: The Author, based on Lim, Carvalho [18]

\begin{tabular}{|c|c|c|c|}
\hline \multicolumn{2}{|c|}{ Learning Mechanics (LM) } & \multicolumn{2}{|c|}{ Game Mechanics (GM) } \\
\hline $\mathrm{a}$ & Instructional & 1 & Story Line / Scenes \\
\hline $\mathrm{b}$ & Tutorial & 2 & Tutorial \\
\hline $\mathrm{d}$ & $\begin{array}{l}\text { Explore } \\
\text { Identify } \\
\text { Discover }\end{array}$ & 5 & $\begin{array}{l}\text { Select } \\
\text { Collect } \\
\text { Questions / Answer }\end{array}$ \\
\hline$f$ & $\begin{array}{l}\text { Speculate / Discuss } \\
\text { Responsibility } \\
\text { Ownership } \\
\text { Accountability }\end{array}$ & 6 & $\begin{array}{l}\text { Competition } \\
\text { Cooperation/Collaboration } \\
\text { Managing Results } \\
\text { Goods/ Information }\end{array}$ \\
\hline $\mathrm{g}$ & Feedback & 7 & Feedback / Checkpoint \\
\hline $\mathrm{c}$ & Orientation / Observation & 3 & Capture / Eliminate \\
\hline $\mathrm{e}$ & Motivation & 4 & Time pressure \\
\hline $\mathrm{h}$ & Repetition & 8 & Dynamic behaviors \\
\hline i & Incitement & 9 & Statistics \\
\hline
\end{tabular}

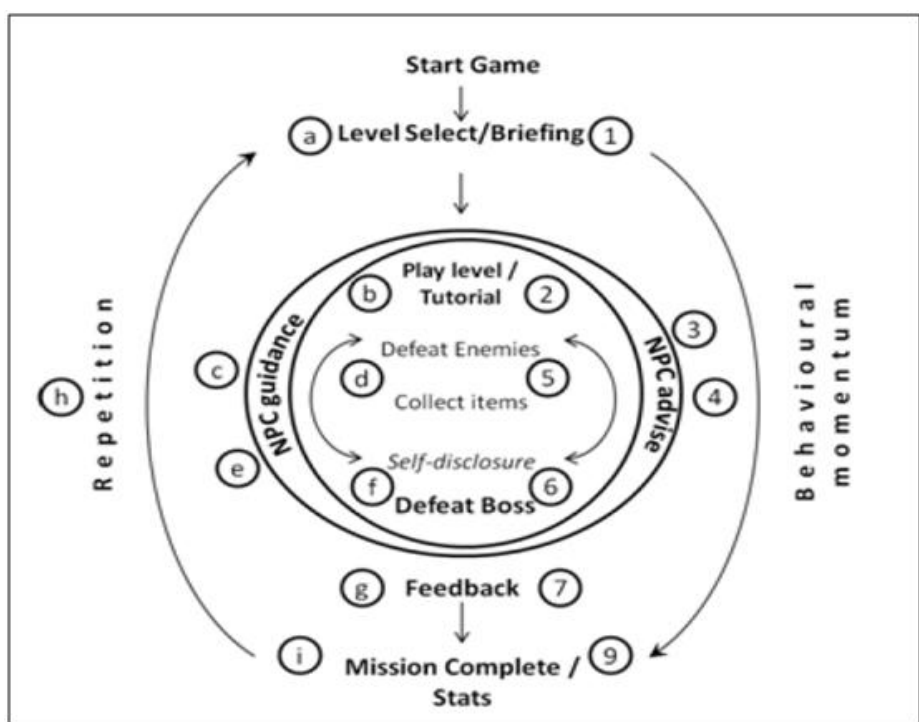

Figure3-The game map constructed through an LM-GM based analysis. Font: Author, based on Lim, Carvalho.[18] 


\subsection{Technological choices}

In order to choose the project's technologies, there are two that need to be considered: the tool's cross-platform feature or technology and the project's compatibility with GNU (General Public License).

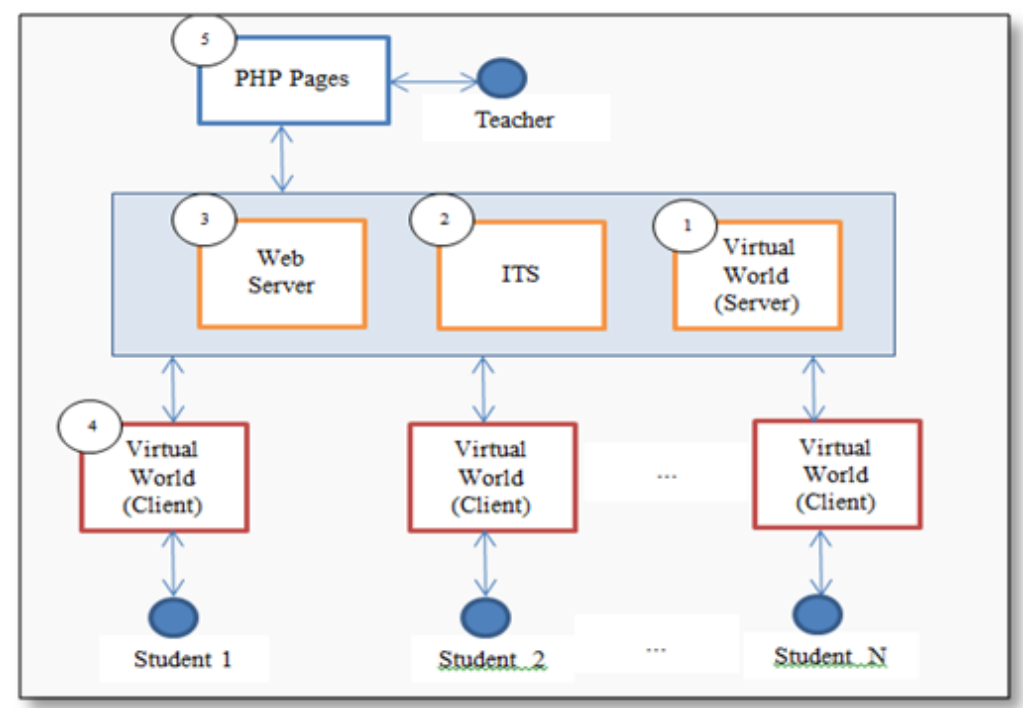

Figure 4 - Project diagram. Font: [20]

Fig. 3, shows the project technological structure representation applied, from which it is important to highlight and comment the items related to numbers 1 to 5 , namely:

\section{(1) 3D Virtual World (Server):}

It is the Virtual 3D Environment Server. This server is responsible for centralizing the execution of certain programs (more general and complex) that allow the availability and execution of virtual environment on client machines. As a Virtual World Server, we chose to use the OpenSimulator, also known as OpenSim, in this project.

OpenSim is an open source, cross-platform and multiuser application server. It can be used to create customized 3D virtual environments (worlds) that can be accessed through a variety of clients in multiple protocols.

Written in C \# language, it runs on both the Windows operating system (.NET framework) and the Unix operating system (Mono framework). The source code is released under the BSD (is open-source license Berkeley SoftwareDistribution) license.

Characteristics:

- Supports 3D environments, online and multiuser;

- Supports multiple clients and protocols;

- Supports physical simulations in real time;

- Supports clients that create 3D content in real time;

- Supports scripts;

- Provides unlimited ability to customize virtual world applications;

- It can be run on a unique machine or on the same machine as a client viewer.

\section{(2) Intelligent Tutors System:}

The ITS of this project was developed in two parts: The operational part, developed in LSL (Linden Scripting Language), a script language available in the OpenSim Viewer itself, contemplating the logics and strategies of acting and targeting according to the performance and reactions of the learners. The second part, related to the interface with teachers and students (Web pages), developed in PHP language, which, besides the interface, is also responsible for communication with the Database (MySQL).

\section{(3) Web Server:}

Web servers are software-specific computers that allow to accept requests from client computers and return responses to those requests. Web servers also allow to share information over the Internet, over an intranet or extranet. In this project the Web Server will be simulated by the application WampServer, which is a web development environment for the Windows operating system that allows the creation of web applications with PHP and MySql database. 
(4) 3D Virtual World (Client):

Viewer Imprudence was first chosen as a virtual world "viewer" (open source), based on the open sources of Second Life viewers. However, Viewer Imprudence has limitations with regard to making videos available on objects within the scenario. So, it waschanged toFireStorm Viewer, which turned out to be much better and not heavier than the previous one.

\section{(5) PHP Pages:}

The web pages developed in PHP language is the ITS's interface between the teacher and the Virtual World. As already mentioned in this document, STI will assist the teacher or tutor in verifying and analyzing student performance within the virtual world. The data collected by the STI will be stored in MySQL Database or in NoteCards within objects in the virtual world. In web pages the teacher can have a friendly interface to this data and can issue reports as well as change configurations and / or strategies predefined in the STI by the instructional designer.

\section{Experimentation}

The experimentation of the project was carried out through presentations, which followed the following sequence:

\section{- Introduction to Project Idea:}

The project ideas were presented as well as their motivation. It was also presented how the characteristics made available in the learning objects and in the project scenario had a direct correlation with the "good practices" established by professors, designers and researchers consulted and evidenced in the bibliographic review and the theoretical foundation.

\section{- Project Experimentation:}

After thevirtual campus map's presentation, the listener is invited to control the avatar within the environment.

While the listener experiences environment control and demonstrates its navigability and avatar control characteristics, some Immersive Learning Scenario'simportant points are highlighted, namely:

- Start of the Game: Portal of entrance of the game;

- Training Center: In-campus environments intended to train / inform the user;

- Access Portals: Ports that allow access through knowledge verification;

- Teachers' Room: Photos, videos and curriculum of each teacher;

- Central Tower: Tower that allows access to each floor (level) of the campus. Each level is specified by color and handles a particular subject;

In order to be self-sufficient and to promote self-learning, all sectors / wings / rooms / corridors of the island have been designed to facilitate understanding of what needs to be done which is the next step to be taken by the avatar. In this sense, you can see a poster informing the player, in case he needs it, that to carry out the basic control of his avatar the arrow keys must be used.

The Fig.5, below, shows the campus map.

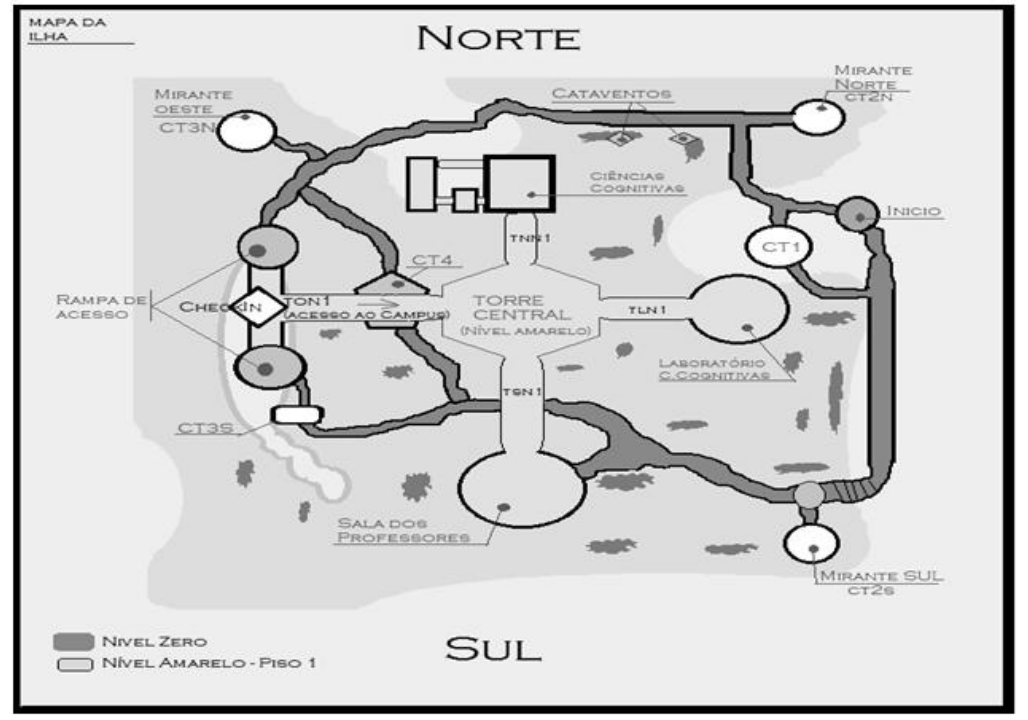

Figure 5 - Campusmap (ground and the first floor of the campus). Font: The Author 
The Fig.6 shows the game's starting point.

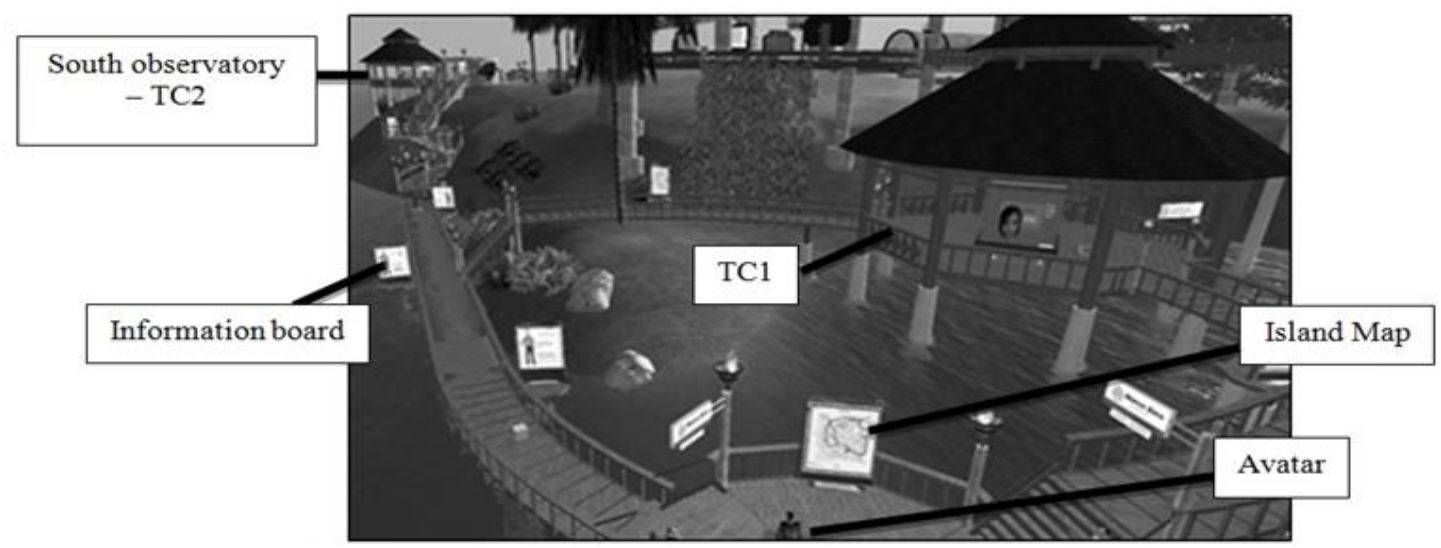

Figure 6-Game's starting viewpoint. Font: The Author.

The campus is divided as follows: The first floor or Yellow Level: Cognitive Sciences. The Second Floor or Red Level deals with Learning Theories. In this same floor are also dealt with subjects related to the discipline of Learning Neurosciences. The Third Floor or Blue Level deals with Artificial Intelligence.The Fig.7, below, shows the first and second floors.

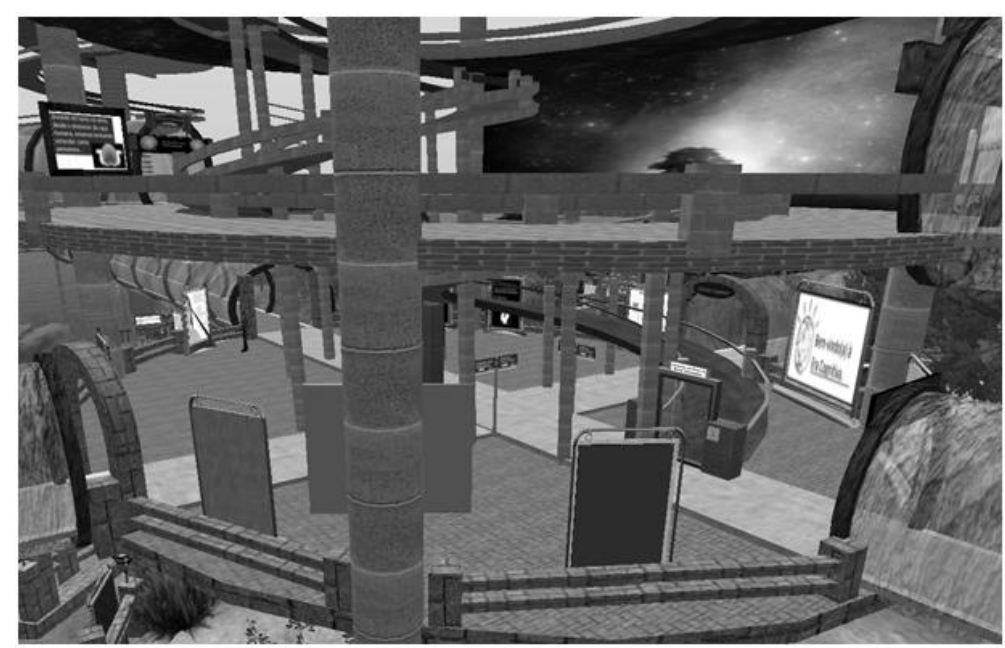

Figure 7 - The central tower -first and second floors. Font: The Author.

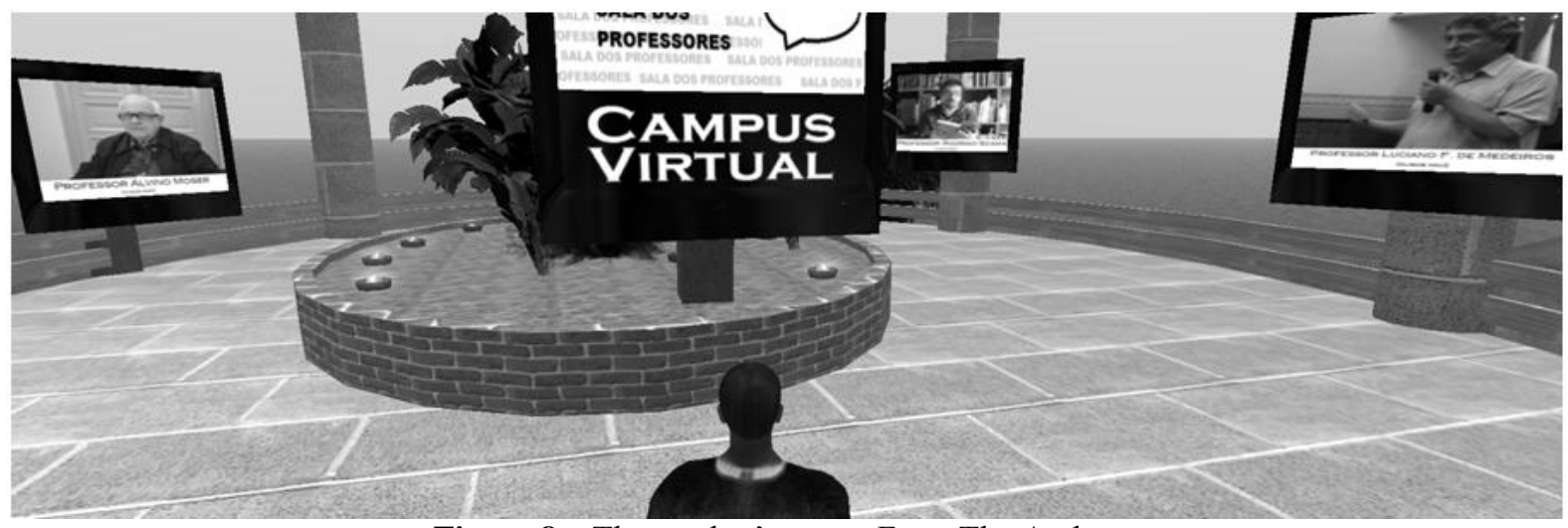

Figure 8 - The teacher's room. Font: The Author. 


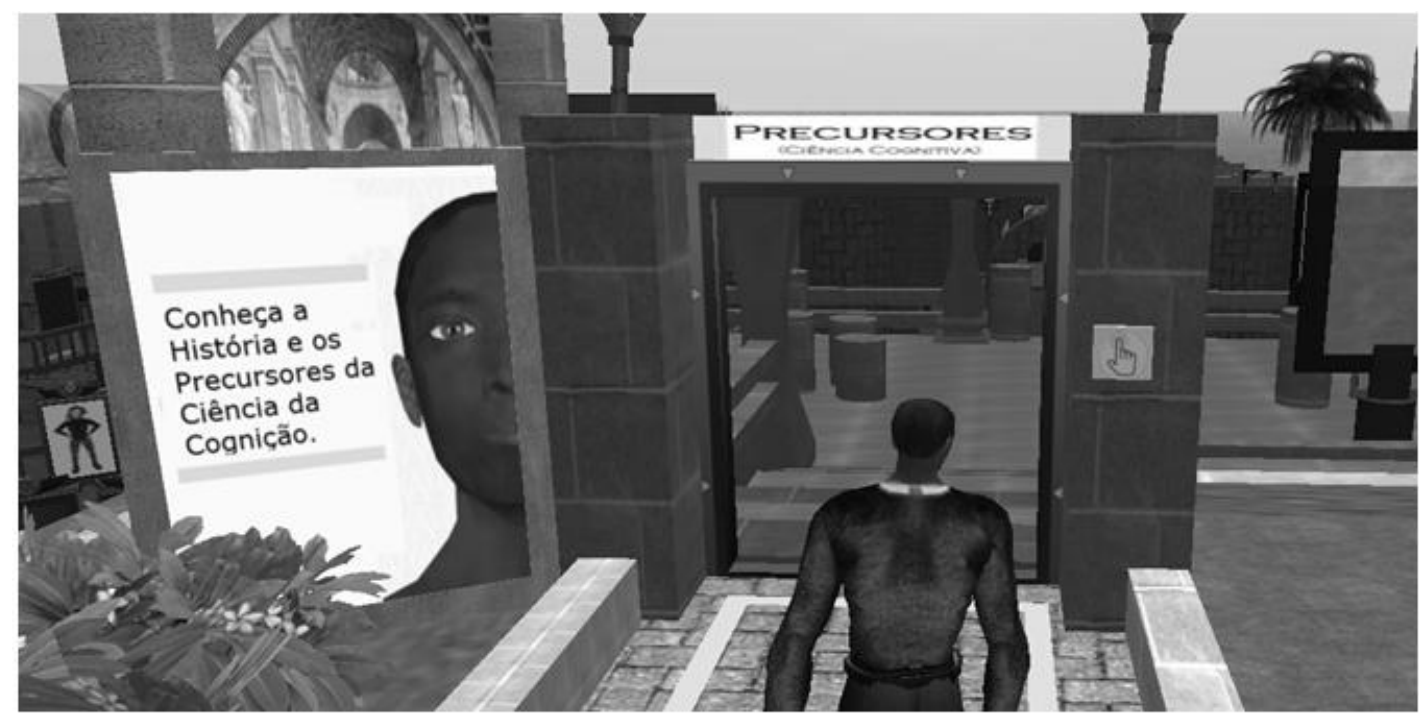

Figure 9- Player's avatar in front of anaccess portal. Font: The Author.

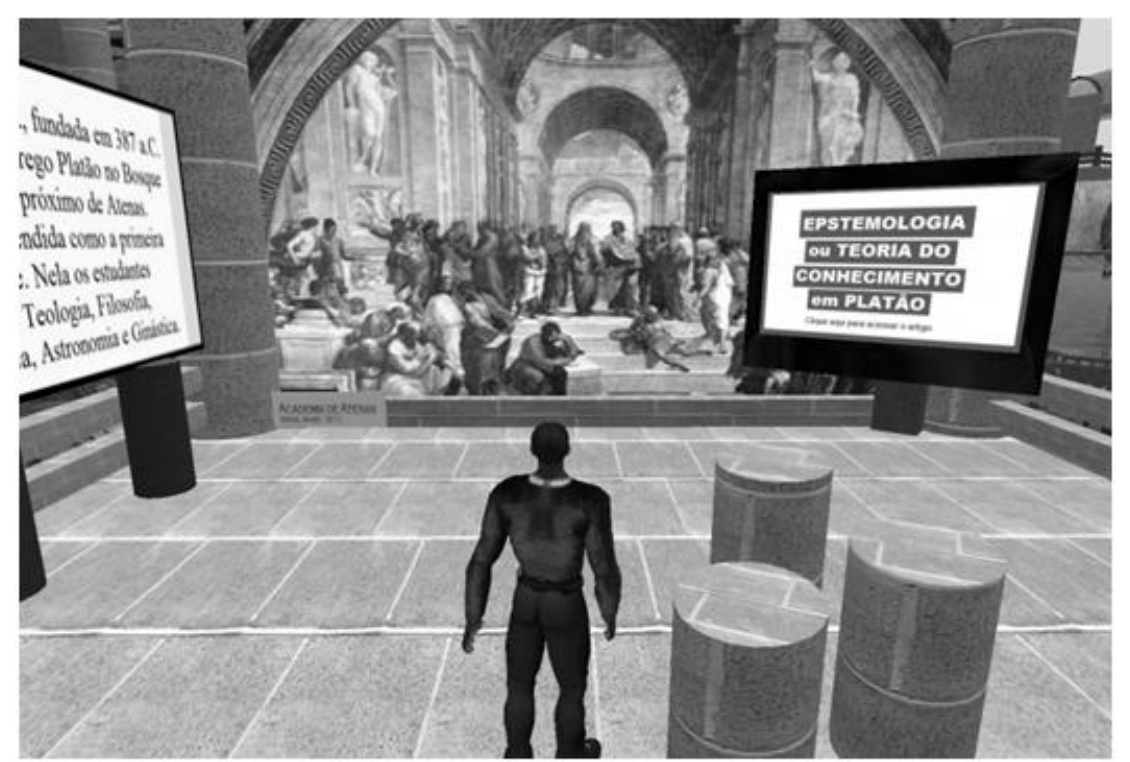

Figure 10 - Cognitive science's introduction area. Font: The Author.

\section{Final Considerations}

The main purpose of this project was to contribute to a better understanding of how the immersive 3D virtual environments can be useful both in the availability of contents, in the interactivity between students and teachers, in the collaboration of the students themselves, in the accomplishment of knowledge tests and improving the quality of the evaluation.

The structure of the project was based on the LM-GM (Learning Mechanisms - Game Mechanisms) model, according to Lim and Carvalho (2012) and a questionnaire with a Likert scale, composed of twenty three objective items and two descriptive items, from which we draw some considerations, namely: Firstly, it has been found that the impact caused by the Immersive Learning Scenario in three dimensions is in itself something that draws the attention of both the student and the teacher and greatly increases the interest inthe process' understanding and participating. The proposed friendly interface needs improvement and an educational designer will be needed to improve the players'sense of confidence, so that they do not feel difficult to understand what to do to take the next step. The Location Map, its information and placements were well evaluated, although, as reported by the interviewees, positioning the location map should not be a concern of the game designer. It should always be available, via shortcut key, on the game display itself when the player feels it is necessary.

Another characteristic identified by the collection was that the teachers and students interviewed could imagine themselves using the resources of the environment as a learning aid in a wide range of educational methodologies and agreed that the product enables the student to approach with learning and research. 
Future research could use the questionnaire in larger samples, whether focusing on other levels of education (undergraduate, high school, etc.) or even within other disciplines. Another important item for future implementation is the proposed ITS thathas been partially implemented. The development of a robust ITS could actually be the complete differential for this AVI-3D.

\section{References}

[1]. Fabiano N. OLIVEIRA. (2013, Out.) Fábrica de Jogos. [Online]. http://www.fabricadejogos.net/posts/artigo-gameficacaoresolvendo-problemas-reais-com-elementos-de-games/

[2]. (2017) New Media Consortium. [Online]. https://www.nmc.org/publication/nmc-horizon-report-2017-higher-education-edition/

[3]. Luciano MEIRA. (2012, Set.) Porvir - Série Diálogos: O futuro se aprende. [Online]. http://porvir.org/porpensar/precisamos-mudardna-da-educacao/20121022.

[4]. Gabe ZICHERMANN. (2012, Ago.) TEDxBerlin. [Online]. https://www.youtube.com/watch?v=Axk5-i8oTIU

[5]. Adelina MOURA and Ana Amélia CARVALHO, "Enquadramento Teórico para a Integração Móveis em Contexto Educativo.," in I Encontro Internacional TIC e Educação., Guimarães, 2010, pp. 1001 - 1006. [Online].

http://repositorium.sdum.uminho.pt/handle/1822/11140

[6]. Clarck C. ABT, Serious Games. London: University Press of America, 1987.

[7]. Hyacinth S. NWANA, "Intelligent Tutoring Systems: an overwiew," Artificial Intelligence Review, vol. 4, pp. 251-277, 1990.

[8]. Richard M. RYAN and Edward L. DECI, "Self-Determination Theory and the Facilitation of Intrinsic Motivation, Social Development, and Well-Being.," American Psychologis, vol. 55, pp. 68-78, Jan 2000, https://home.ubalt.edu/tmitch/641/deci_ryan_2000.pdf.

[9]. Johan HUIZINGA, Homo Ludens, 4th ed. São Paulo, SP, Brasil: Perspectiva, 2000.

[10]. George SIEMENS. (2004, dez) ELearnSpace - Everything elearning. [Online]. http://www.elearnspace.org/Articles/connectivism.htm

[11]. Kurt VANLEHN, "The Behavior of Tutoring Systems," International Journal of Artificial Intelligence in Education, vol. 16, no. 3, pp. 227-265, Aug. 2006.

[12]. Roger NKAMBOU, Jacqueline BOURDEAU, and Valery PSYQUÉ, "Building Intelligent Tutoring Systems:An Overview," in Advances in Intelligent Tutoring Systems. Berlin: Springer-Verlag, 2010, ch. 18th, pp. 361-375.

[13]. Marc PRENSKY, Aprendizagem Baseada em Jogos Digitais. São Paulo: SENAC, 2012.

[14]. Amy Jo KIM. (2012, Set) Innovate with Game Thinking. [Online]. http://amyjokim.com/blog/2012/09/14/the-players-journeydesigning-over-time/

[15]. James P. GEE, Good Video Games and Good Learning: Collected essays on video games, learning and literacy., 2nd ed. New York, NY, USA: Peter Lang Publishing, Inc, 2013.

[16]. Arthur GRAESSER, "A Guide to Understand Learner Models," in Design Recommendations for Intelligent Tutoring Systems: Learner Modeling. Orlando, Florida, USA: U.S. Army Research Laboratory, 2013, vol. 1, ch. 1, p. 277.

[17]. Susana CARREIRA, "Matemática e Tecnologias - Ao encontro dos "Nativos Digitais" com os "Manipulativos Virtuais"," Quadrante - Revista de Investigação em Educação Metemática, vol. XVIII, pp. 53-86, 2009.

[18]. Theodore LIM, Maira B. CARVALHO, Sylvester ARNAB, Francesco BELlOTTI, and Sara de FREITAS. (2012) CiteSeerx. [Online]. http://citeseerx.ist.psu.edu/viewdoc/summary?doi=10.1.1.678.6172

[19]. Eduardo CHAVES, "TEcnologia na Educação, Ensino a Distância e Aprendizagem Mediada pela Tecnologia: Conceituação Básica," Revista Educação, vol. 3, pp. 29-43, 1999.

[20]. Alvino MOSER, Luciano Frontino MEDEIROS, and Luiz Fernando CORCINI, "Changing Ways for a Better Education: A 3D Gamified Virtual Learning Environment (VLE)," ATINER's Conference Paper Series , vol. EDU2016-1945, Ago. 2016, (Fonte Disponível em: http://www.atiner.gr/papers/EDU2016-1945.pdf - acesso em: 26/11/2016).

[21]. Rabia YILMAZ, Burcu TOPU, Yuksel GOKTAS, and Murat COBAN, "Social Presence and Motivation in a three-dimensional virtual world: A explanatory study.," Australasian Journal of Education Technology, vol. 29, pp. 823-839, 2013, Disponível em: http://ajet.org.au/index.php/AJET/article/view/425/778 - Acessado em: 28/10/2015.

[22]. Íthalo MOURA, Franscisco MENDES, and Paulo; SOUZA, "Utilização do Framework JADE no Desenvolvimento de um Mudeo Virtual.," Exacta, 2012, Disponível em : www.unibh.br/revistas/exacta - acessado em: 28/10/2015.

[23]. Antonio Siemsen MUNHOZ, ABP - Apredizagem Baseada em Problemas - Ferramentas de apoio ao Docente no Processo de Ensino-Aprendizagem., 1st ed. São Paulo, SP, Brasil: Ceagage Learning, 2015.

[24]. Jorge Juan Zavaleta GAVIDIA and Leila C. Vasconcelos de ANDRADE, "Sistemas Tutores Inteligentes. [Intelligent Tutoring System.]," Universidade Federal do Rio de Janeiro, Rio de Janeiro, Monografia 2003.

[25]. Hugh L. BURNS and Charles G. CAPPS, "Foundation od Intelligent Tutoring Systems: An Introduction," in Foundation od Intelligent Tutoring Systems. Hillsdale, New Jersey, USA: Lawrence Erlbaum Associates, Inc., 1988, ch. 1, pp. 1-20.

[26]. Richard BARTLE, "Virtual Worlds: Why People Play," MMP Game Development, p. 16, 1996, (Fonte: http://mud.co.uk/richard/VWWPP.pdf - acesso em: 01/02/2016).

[27]. Andrzej MARCZEWSKI, Gamification: A Simple Introdution \& a Bit More.: author, 2013.

[28]. Amy Jo KIM. (2014) What makes games compelling? [Online]. http://amyjokim.com/blog/2014/04/07/what-makes-gamescompelling/

[29]. Karl M. KAPP, The Gamificarion of Learning and Instrution. São Francisco, CA, EUA: Pfeiffer, 2012.

[30]. Jeniffer GROFF, Hanna DUMMONT, David INSTANCE, and Francisco BENAVIDES, "The Nature of Learning - Using Reseach to Inspire Practice," OECD, Practioner Guide 2012.

[31]. Luiz Fernando CORCINI, "Cenários Imersivos de Aprendizagem: A construção do Conhecimento em Ambiente de PósGraduação.," PPGENT - Programa de Pós Graduação em Educação e Novas Tecnologias, UNINTER, Curitiba, Dissertação 2016 